Supporting Information

\title{
Nanoscale Covalent Organic Framework for Combinatorial Antitumor Photodynamic and Photothermal Therapy
}

Qun Guan, ${ }^{\dagger, \ddagger}$ Le-Le Zhou, ${ }^{\dagger, \#, \ddagger}$ Yan-An Li, ${ }^{\dagger}, *$ Wen-Yan Li, ${ }^{\dagger}$ Shumei Wang,,${ }^{\S}$ Chun Song, ${ }^{\S}$ and Yu-Bin Dong ${ }^{\dagger, *}$

$\uparrow$ College of Chemistry, Chemical Engineering and Materials Science, Collaborative Innovation Center of Functionalized Probes for Chemical Imaging in Universities of Shandong, Key Laboratory of Molecular and Nano Probes, Ministry of Education, Shandong Normal University, Jinan 250014, P. R. China.

\# School of Chemical and Biological Engineering, Qilu Institute of Technology, Jinan 250200, P. R. China.

$\S$ Department of Medicinal Chemistry, School of Pharmaceutical Sciences, Shandong University, Jinan 250012, P. R. China.

† Q.G. and L.-L.Z. contributed equally to this work. 


\section{Materials and Instrumentations}

1,3,5-Tris(4-aminophenyl)benzene and 2,5-dimethoxyterephthaldehyde were purchased from Jilin Province Yanshen Technology Co., Ltd. 1,3-Diphenylisobenzofuran (DPBF) were purchased from TCI (Shanghai) Development Co., Ltd. 5-(4-Aminophenyl)-10,15,20triphenylporphyrin (Por) were purchased from Frontier Scientific, Inc. Polyvinyl pyrrolidone $\left(M_{w}=8000\right)$, acetic acid and benzaldehyde were purchased from Aladdin Reagent Co., Ltd. Vanadyl 2,11,20,29-tetra(tert-butyl)-2,3-naphthalocyanine (VONc) was purchased from Sigma-Aldrich (Shanghai) Trading Co. Ltd. All reactants were used as purchased without further purification.

All organic solvents were purchased from Sinopharm Chemical Reagent Co., Ltd. Ultra-pure water was prepared with an Aquapro System (18 M $\Omega)$.

3-(4,5-Dimethyl-2-thiazolyl)-2,5-diphenyl-2H-tetrazolium bromide (MTT) were purchased from Sigma-Aldrich (Shanghai) Trading Co. Ltd. Calcein $O, O^{\prime}$-diacetate tetrakis(acetoxymethyl) ester (calcein-AM) and propidium iodide (PI) were purchased from Yeasen Biotech (Shanghai) Co., Ltd. Hoechst 33258 and acridine orange hydrochloride (AO) were purchased from MedChemExpress Co. Ltd. Singlet Oxygen Sensor Green (SOSG), 5,5',6,6'-tetrachloro-1,1',3,3'-tetraethylbenzimidazolylcarbocyanine iodide (JC-1), LysoTracker Red DND-99, MitoTracker Deep Red FM, MitoTracker Red CM- $\mathrm{H}_{2}$ Xros were purchased from Thermo Fisher Scientific Inc.

Phosphate-Buffered Saline (PBS), Dulbecco's Phosphate-Buffered Saline (DPBS), and Fetal Bovine Serum (FBS) were purchased from Biological Industries USA, Inc. Dulbecco's Modified Eagle Medium (DMEM), Penicillin Streptomycin Mixtures (Pen-Strep), and Trypsin-EDTA Solution (0.25\%) were purchased from HyClone Laboratories, Inc. Normocin was purchased from Invivogen (San Diego, CA, USA).

The red LED lamp was purchased from Shenzhen Ouying Lighting Electric Co., Ltd. The 808 nm laser (FC-808-2000-MM) was purchased from Shanghai Xilong Optoelectronics Technology Co., Ltd.

Fourier transform infrared (FT-IR) spectra were obtained in the $4000-400 \mathrm{~cm}^{-1}$ range using a Thermo Scientific Nicolet iS50 FT-IR Spectrometer equipped with diamond attenuated total reflection (ATR) module. Each spectrum was the average of 16 scans. Ultraviolet-visible (UV-vis) absorption spectra were recorded on a Shimadzu UV-2700 Double Beam UV-vis Spectrophotometer. Electron paramagnetic resonance (EPR) spectra were recorded on a Bruker A300 EPR Spectroscopy. Scanning electron microscopy (SEM) micrographs were recorded on a Hitachi SU8010 Scanning Electron Microscope. Transmission electron microscope (TEM) micrographs were recorded on a Hitachi HT7700 120kV Compact-Digital Transmission Electron Microscope. Atomic force microscopy (AFM) was conducted on Cypher VRS AFM (Oxford Instruments). Powder X-ray diffraction (PXRD) patterns were obtained on a Rigaku SmartLab SE X-Ray Powder Diffractometer with $\mathrm{Cu} \mathrm{K} \alpha$ line focused radiation $(\lambda=1.5405 \AA)$ from $2 \theta=2.00^{\circ}$ up to $50.00^{\circ}$ with $0.01^{\circ}$ increment. Nitrogen adsorption isotherms were measured at $77 \mathrm{~K}$ with a Micromeritics ASAP2020 HD88 Surface Area and Porosity Analyser. Before measurement, the samples were degassed in vacuum at $120^{\circ} \mathrm{C}$ for $12 \mathrm{~h}$. The BrunauerEmmett-Teller (BET) equation was utilized to calculate the specific surface areas. The pore size distribution was derived from the sorption curve by using the non-local density functional theory (NLDFT) model. Hydrodynamic particle size and zeta potential were measured using Malvern Zetasizer Nano ZS90 System. Inductively coupled plasma (ICP) measurements were obtained on Thermo 
Scientific iCAP 7000 ICP-OES. Laser scanning confocal fluorescence images were captured with a Leica TCS SP8 Confocal Laser Scanning Microscopy with an objective lens $(\times 20)$. Glass bottom dishes were purchased from Cellvis (Mountain View, CA, USA). Microplate assays were carried out on a Molecular Devices SpectraMax i3x Multi-Mode Microplate Detection System.

\section{Cell Culture and Laboratory Animals}

The MCF-7 (human breast adenocarcinoma cell line) was provided by Stem Cell Bank, Chinese Academy of Sciences (Shanghai, P.

R. China), and cultured in DMEM supplemented with FBS (10\%), Normocin (50 $\mu \mathrm{g} / \mathrm{mL})$, penicillin (100 U/mL) and streptomycin $(100 \mu \mathrm{g} / \mathrm{mL})$ in an atmosphere of $\mathrm{CO}_{2}(5 \mathrm{vol} \%)$ and air $(95 \mathrm{vol} \%)$ at $37^{\circ} \mathrm{C}$.

Nude mice (BALB/c-nu, femina, aged 4 weeks, 15-20 g) were purchased from the Beijing Vital River Laboratory Animal Technology Co., Ltd. Animal experiments were reviewed and approved by the Ethics Committee of Shandong Normal University (Jinan, P. R. China). All the animal operations complied with Chinese government relevant guidelines and regulations for the care and use of experimental animals.

\section{Por and VONc Contents}

After synthesis, the supernatants were collected by centrifugation, and all the washing liquids produced during the washing process were collected. The contents of Por and VONc in the supernatant and the washing liquid were calculated using standard curves. These contents were subtracted from the total reactants to obtain the Por and VONc contents in $\mathbf{2}$ and $\mathbf{3}$, respectively.
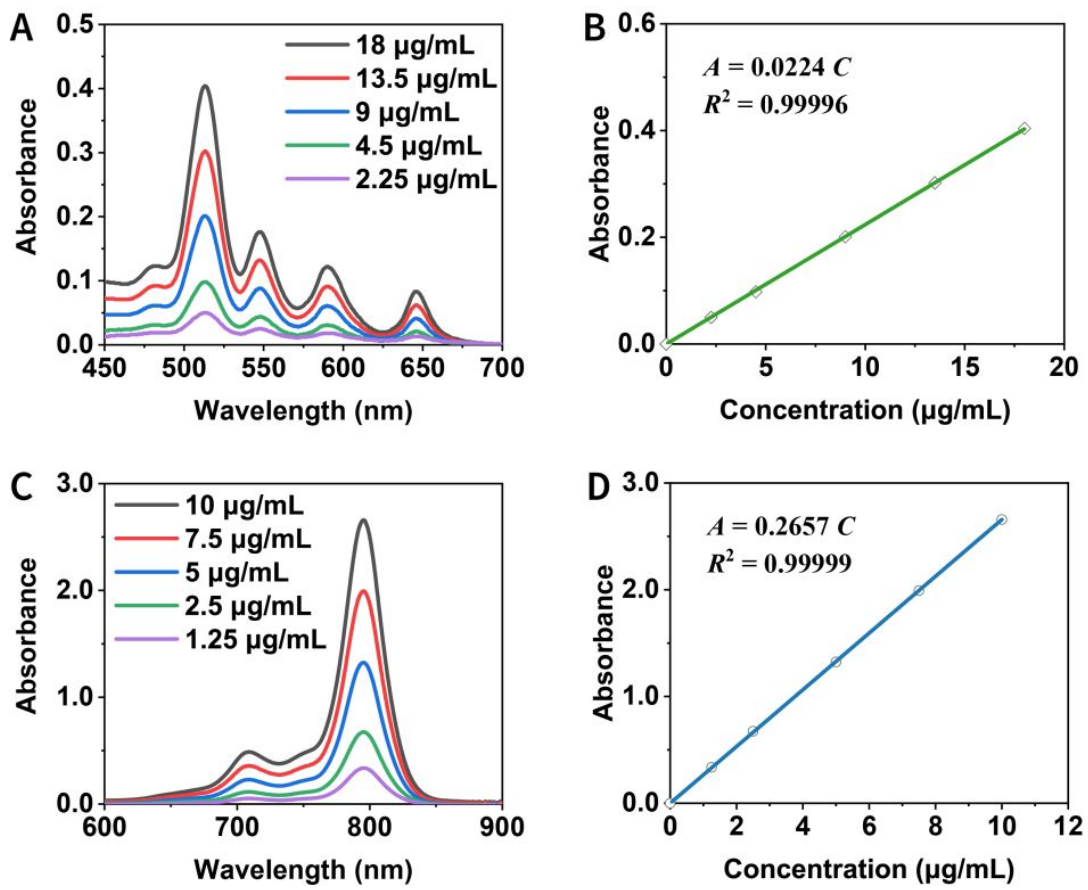

Figure S1. (A) UV-vis spectra of Por in 1,4-dioxane. (B) Standard curve of Por in 1,4-dioxane. (C) UV-vis spectra of VONc in DMAC. (D) Standard curve of VONc in DMAC. 


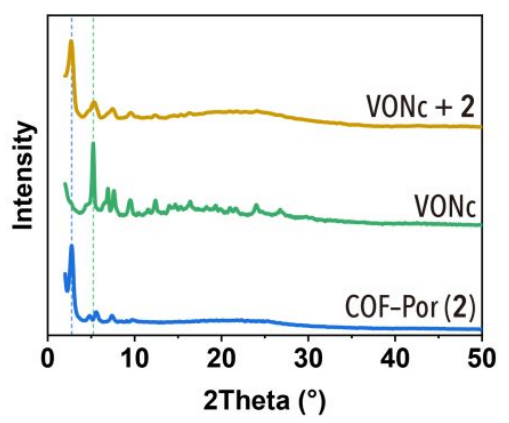

Figure S2. Powder X-ray diffraction (PXRD) patterns of a mixture of VONc and 2.

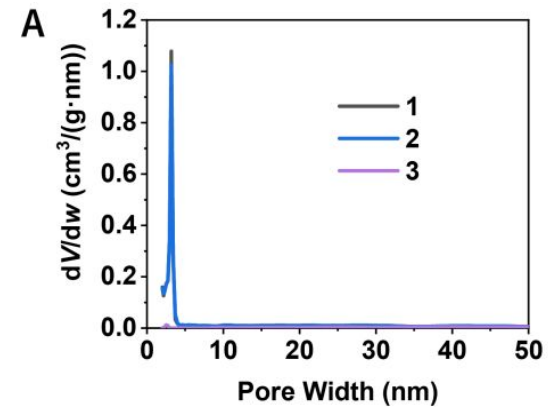

\begin{tabular}{lll}
\hline & \multicolumn{1}{l}{$\boldsymbol{S}_{\text {BET }}$} & Main Pore Size \\
\hline $\mathbf{1}$ & $1217 \mathrm{~m}^{2} / \mathrm{g}$ & $3.2 \mathrm{~nm}$ (narrow) \\
$\mathbf{2}$ & $1180 \mathrm{~m}^{2} / \mathrm{g}$ & $3.2 \mathrm{~nm}$ (narrow) \\
$\mathbf{3}$ & $115 \mathrm{~m}^{2} / \mathrm{g}$ & $2.5 \mathrm{~nm}$ (wide) \\
\hline
\end{tabular}

Figure S3. (A) Pore width distribution plots of 1, 2, and 3. (B) BET specific surface area $\left(S_{\mathrm{BET}}\right)$ and main pore size of $\mathbf{1 , 2}$, and $\mathbf{3}$.

\section{Release Experiments}

VONc@COF-Por $(3,2 \mathrm{mg})$ was added to DMAC $(50 \mathrm{~mL})$ or PBS $(50 \mathrm{~mL})$. The dispersion was taken at different times, and the UV-vis spectra of the supernatant were tested after centrifugation and converted to the release rate of VONc using a standard curve.
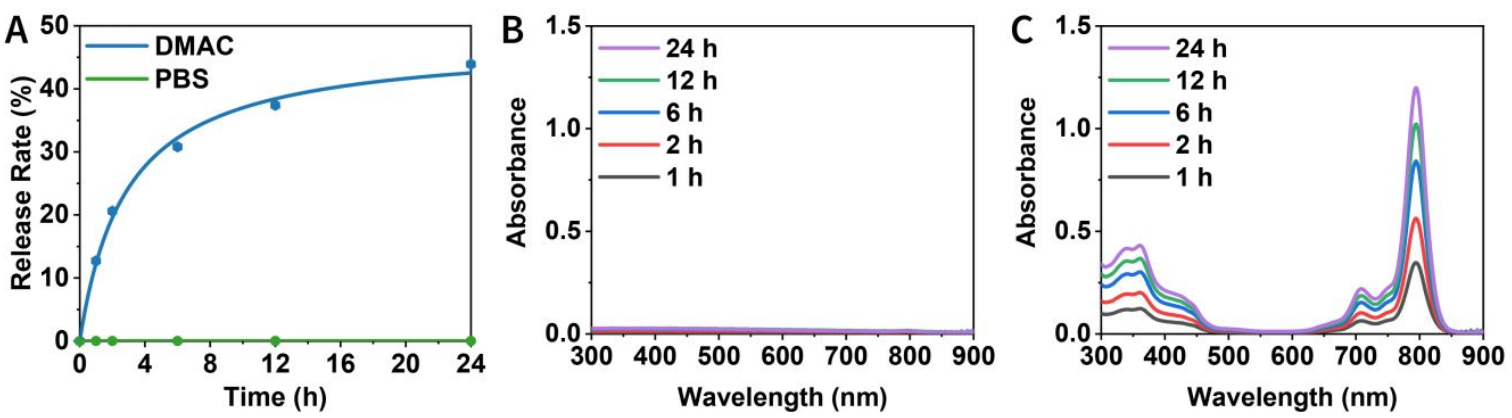

Figure S4. VONc release experiments in DMAC and PBS. (A) VONc release rate as a function of time. (B) UV-vis spectra of the PBS supernatant at different times. (C) UV-vis spectra of the DMAC supernatant at different times.
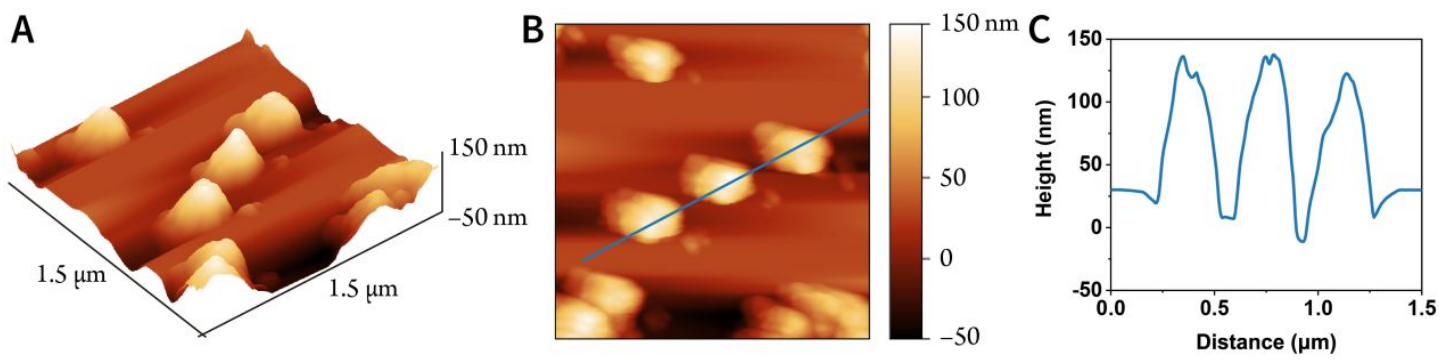

Figure S5. AFM images of 3 (A, B) and its height profile (C) along the blue line. 

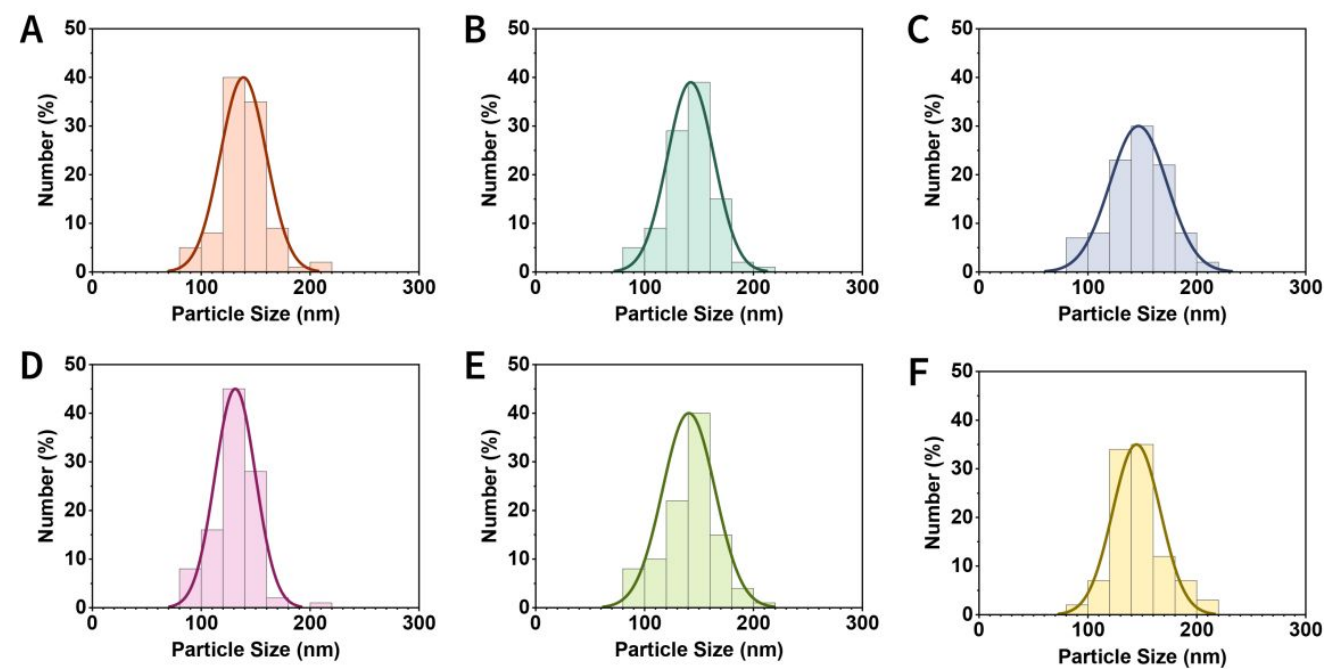

Figure S6. Particle size distribution of 1 (A, D), 2 (B, E) and 3 (C, F) obtained from statistics using SEM (A, B, C) and TEM (D, E, F) images.
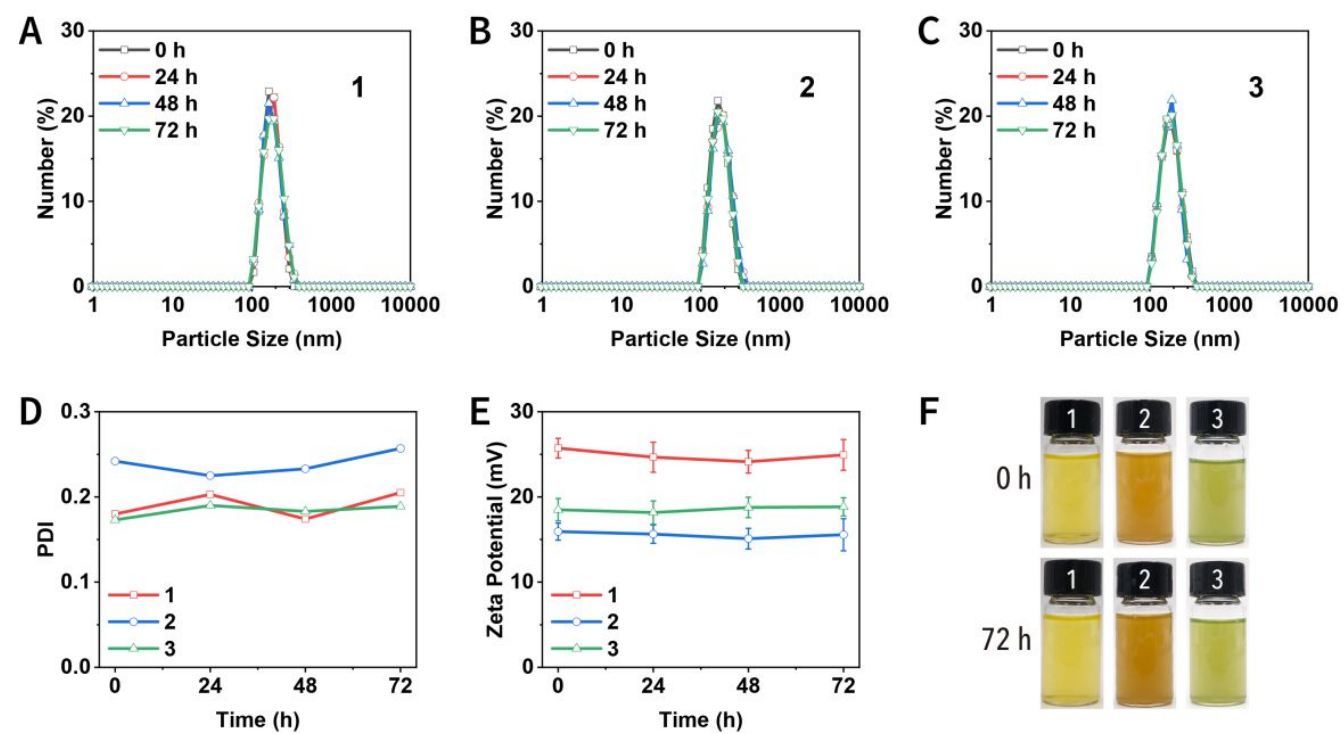

Figure S7. Colloidal Stability. (A, B, C) Particle size profiles measured by DLS of 1 (A), 2 (B), and 3 (C) in PBS (pH = 6.5) at different standing times. (D) PDI measured by DLS of 1, 2, and 3 in PBS ( $\mathrm{pH}=6.5$ ) at different standing times. (E) Zeta potentials of $\mathbf{1}, \mathbf{2}$, and $\mathbf{3}$ in PBS $(\mathrm{pH}=6.5)$ at different standing times. Data was presented as the mean $\pm \mathrm{SD}(n=3)$. (F) Digital photos of $\mathbf{1}, \mathbf{2}$, and 3 in PBS $(\mathrm{pH}=6.5)$ before and after standing for $72 \mathrm{~h}$.
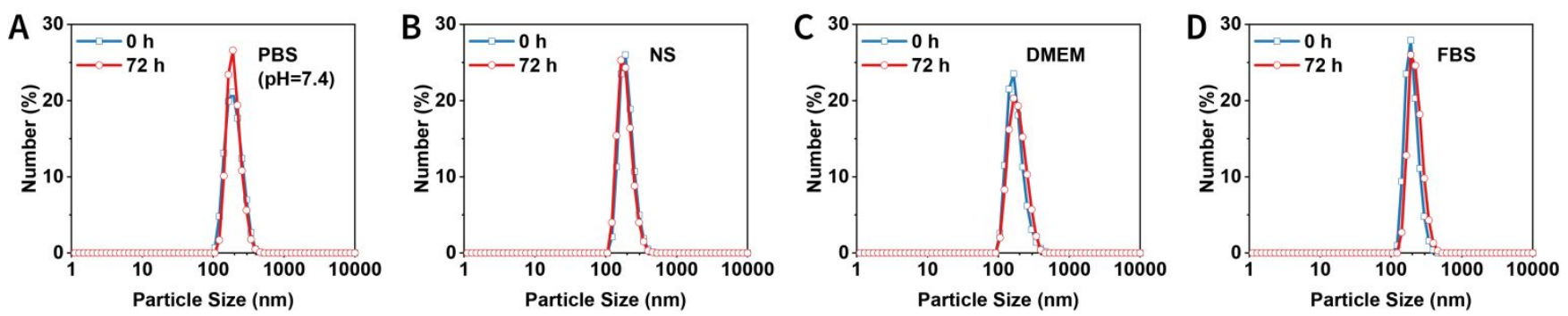

Figure S8. Particle size profiles measured by DLS of $\mathbf{3}$ in PBS (A), normal saline (B), DMEM (C), and FBS (D) at different standing times. 


\section{Photodynamic Property}

The dispersion of $3(2 \mathrm{~mL}, 40 \mu \mathrm{g} / \mathrm{mL})$ and DPBF DMF solution $(100 \mu \mathrm{L}, 1 \mathrm{mM})$ were added in a quartz dish and irradiated with a red LED $\left(50 \mathrm{~mW} / \mathrm{cm}^{2}\right)$ or $808 \mathrm{~nm}$ laser $\left(1.5 \mathrm{~W} / \mathrm{cm}^{2}\right)$ for $7 \mathrm{~min}$. The absorbance of DPBF at $414 \mathrm{~nm}$ in the mixture was recorded at $1 \mathrm{~min}$ intervals. The ${ }^{1} \mathrm{O}_{2}$ generation rate was determined from the reduced the absorbance over time. To characterize the difference in the rate of ${ }^{1} \mathrm{O}_{2}$ introduced by different lasers, the ratios $A / A_{0}$ of absorbance $A$ and the initial absorbance $A_{0}$ at 414 nm at different irradiation times were calculated and plotted as the ordinate for the irradiation time. The dispersion of $\mathbf{3}(2 \mathrm{~mL}, 40 \mu \mathrm{g} / \mathrm{mL}) \mathrm{was}$ used as the reference for this UV-vis measurement. To further explore the mechanism of ${ }^{1} \mathrm{O}_{2}$ production, the same experiment was performed with green LED instead of red LED. As expected, green light is more effective in inducing ${ }^{1} \mathrm{O}_{2}$ production than red light (Figure S10), because the first $\mathrm{Q}$ band of Por in green region is higher than $4^{\text {th }} \mathrm{Q}$ band in red region. However, considering that long-wavelength light is more conducive to biological tissue penetration, red light may be a more appropriate choice in PDT of solid tumors.
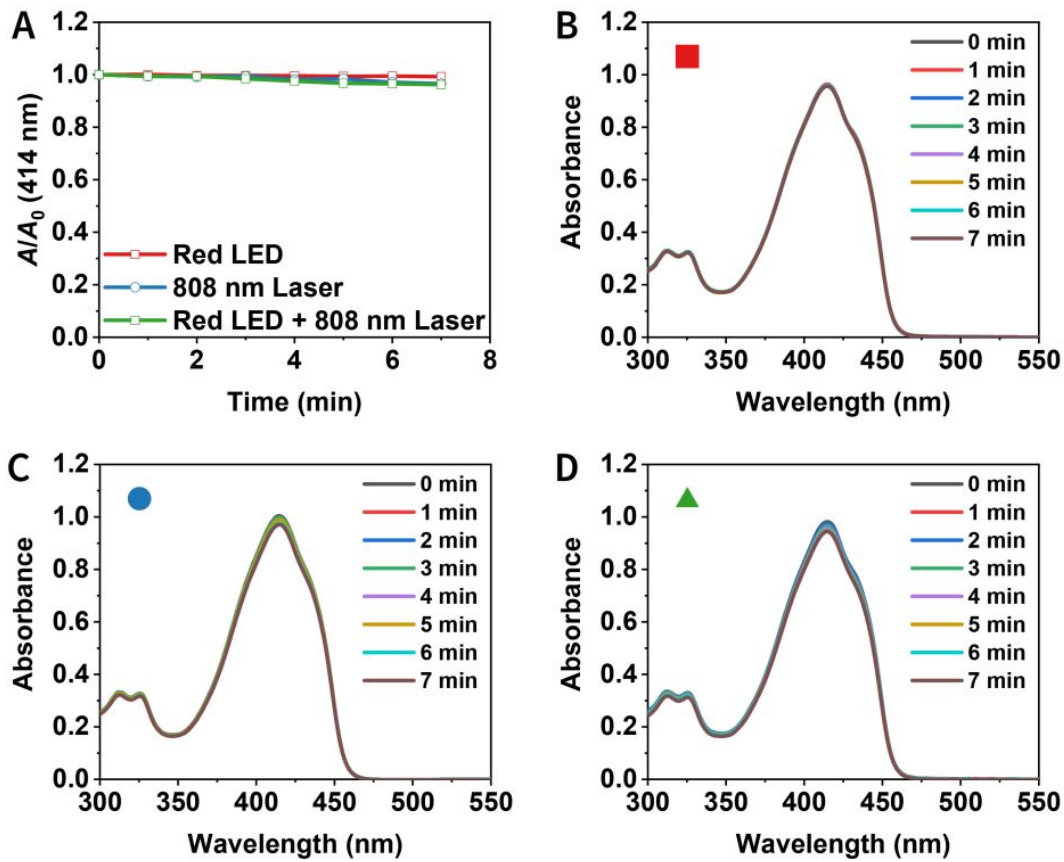

Figure S9. (A) Comparison of the decay rate of DPBF without 3 under a red LED $\left(50 \mathrm{~mW} / \mathrm{cm}^{2}\right)$ and/or an $808 \mathrm{~nm} 1$ aser $\left(1.5 \mathrm{~W} / \mathrm{cm}^{2}\right)$ irradiation. (B, C, D) UV-vis spectra of DPBF under a red LED (B), an $808 \mathrm{~nm}$ laser (C), and red LED+808 nm laser (D).
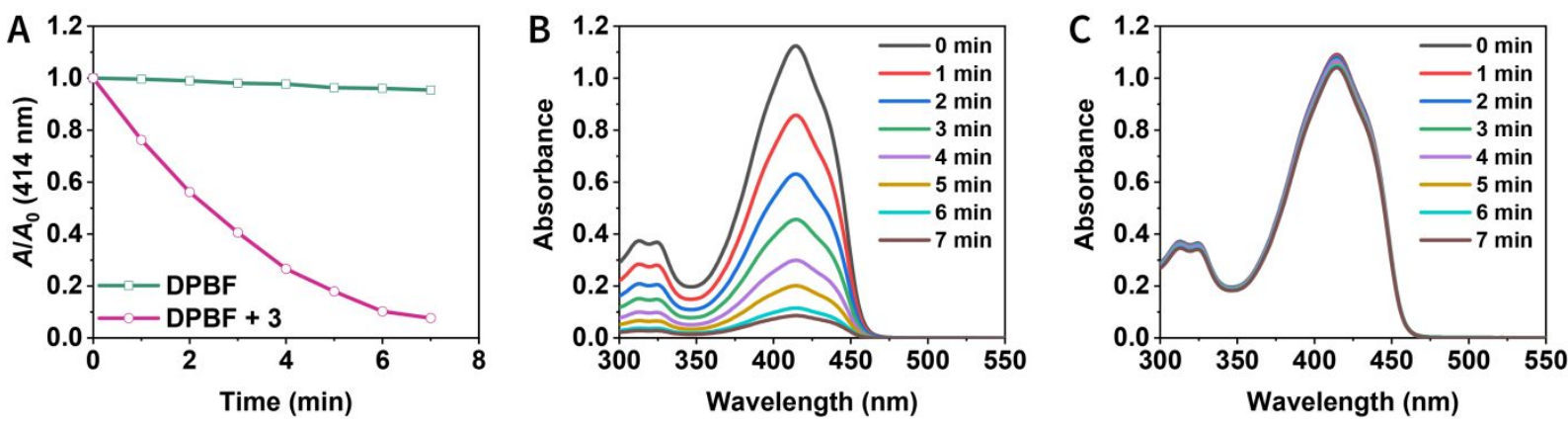

Figure S10. (A) Comparison of the decay rate of DPBF with or without 3 under a green LED $\left(50 \mathrm{~mW} / \mathrm{cm}^{2}\right)$ irradiation. (B) UV-vis spectra of DPBF induced by 3 under a green LED $\left(50 \mathrm{~mW} / \mathrm{cm}^{2}\right)$ irradiation. (C) UV-vis spectra of DPBF without 3 under a green $\operatorname{LED}\left(50 \mathrm{~mW} / \mathrm{cm}^{2}\right)$ irradiation. 


\section{Photothermal Conversion Efficiency}

The PBS dispersion of $3(1 \mathrm{~mL}, 0-600 \mu \mathrm{g} / \mathrm{mL})$ was added in a quartz dish and irradiated with an $808 \mathrm{~nm}$ laser $\left(0-2.0 \mathrm{~W} / \mathrm{cm}^{2}\right)$ for 10 min. Then, the laser was turned off to allow the dispersion to cool naturally. The temperature of the dispersion was recorded at $10 \mathrm{~s}$ intervals.

The photothermal conversion efficiency was calculated according to the following formulas:

$$
\begin{aligned}
& \eta \quad=\frac{Q_{\mathrm{s}}-Q_{\mathrm{w}}}{I\left(1-10^{-A_{808}}\right)} \\
& h S=\frac{m c}{\tau} \\
& Q_{\mathrm{s}}=h S \Delta T_{\mathrm{s}, \mathrm{h}} \\
& \tau \quad=\quad-\frac{\mathrm{d} t}{\mathrm{~d} \ln \theta} \\
& Q_{\mathrm{w}}=h S \Delta T_{\mathrm{w}, \mathrm{h}} \\
& \theta=\frac{T_{t, c}-T_{\min , \mathrm{c}}}{\Delta T_{\mathrm{s}, \mathrm{c}}}
\end{aligned}
$$

$\eta$, photothermal conversion efficiency; $A_{808}$, the absorption of solution at $808 \mathrm{~nm} ; I$, the power of the laser; $\Delta T_{\mathrm{s}, \mathrm{h}}$, the changed temperature of solution in the heating curve; $\Delta T_{\mathrm{w}, \mathrm{h}}$, the changed temperature of water in the heating curve; $c$, specific heat capacity of water; $m$, solution mass; $\tau$, slope of $t-(-\ln \theta)$ graph; $t$, time in the cooling curves; $\Delta T_{\mathrm{s}, \mathrm{c}}$, the changed temperature of solution in the cooling curve; $T_{\min , \mathrm{c}}$, the final temperature of solution in the cooling curve; $T_{t, \mathrm{c}}$, the temperature of solution at different times in the cooling curve.
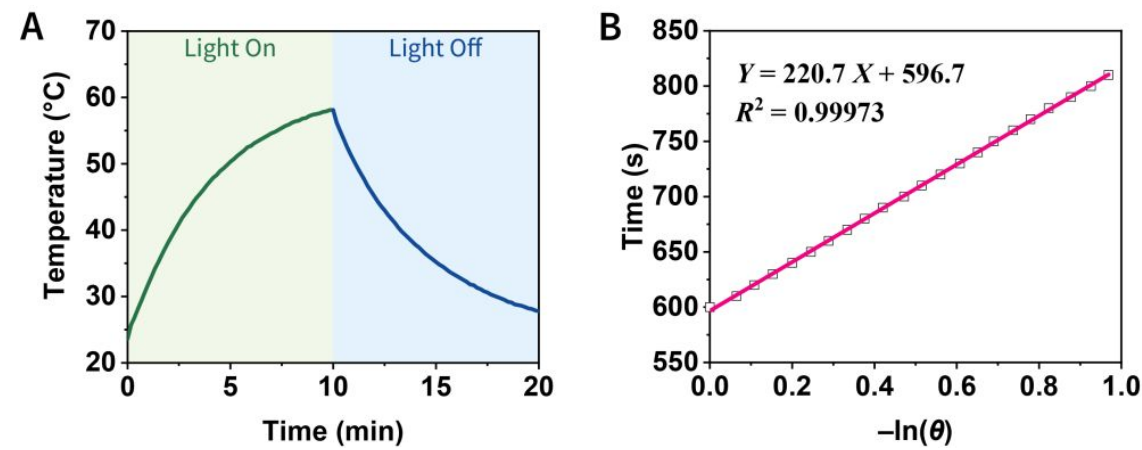

Figure S11. (A) Temperature rises induced by $3(600 \mu \mathrm{g} / \mathrm{mL})$ under an $808 \mathrm{~nm}$ laser $\left(1.5 \mathrm{~W} / \mathrm{cm}^{2}\right)$ irradiation for 10 min and natural cooling for 10 min. (B) The $t-(-\ln \theta)$ graph acquired by the natural cooling period. 
Table S1. NPs with photothermal property based on phthalocyanine (Pc) and naphthalocyanine (Nc).

\begin{tabular}{|c|c|c|c|c|c|}
\hline PTA & Nanocarrier & Material Name & Wavelength/nm & $\eta / \%$ & References \\
\hline $\mathrm{Nc}$ & PEG- $b$-PS & Nanomotor & 808 & - & 1 \\
\hline $\mathrm{SiNc}$ & phospholipid & SiNcOH-DSPE-PEG & 808 & 59.8 & 2 \\
\hline $\mathrm{SiNc}$ & PEG-PCL & SiNc-PNP & 785 & - & 3 \\
\hline $\mathrm{Pc}$ & F127 & 4OCSPC/F127 & 808 & 47.0 & 4 \\
\hline $\mathrm{Pc}$ & 3 kinds of surfactants & FPc & 671 & - & 5 \\
\hline $\mathrm{Pc}$ & $\mathrm{SiO}_{2}$ & Pc@HSNs & 730 & 37.1 & 6 \\
\hline $\mathrm{MnPc}$ & hyaluronic acid & Cur-MnPc@HA & 730 & 72.3 & 7 \\
\hline $\mathrm{PdPc}$ & $\mathrm{SiO}_{2}$ & TR-UCNS & 730 & 54.2 & 8 \\
\hline $\mathrm{FePc}$ & albumin & FePc@HSA & 671 & 44.4 & 9 \\
\hline $\mathrm{ZnPc}$ & porous polymer & SCMP & 785 & 47.0 & 10 \\
\hline $\mathrm{ZnPc}$ & granulesten & $\mathrm{ZnPc-SPC}$ & 638 & - & 11 \\
\hline $\mathrm{ZnPc}$ & PEG-PPG-PEG & Bio-ZnPc-Pdot & 808 & 38.2 & 12 \\
\hline $\mathrm{ZnPc}$ & self-assembly nanoparticles & $\mathrm{ZnPc} N \mathrm{NP}$ & 808 & 31.3 & 13 \\
\hline $\mathrm{ZnPc}$ & self-assembly nanoparticles & DCC@PDCZP & 808 & - & 14 \\
\hline $\mathrm{ZnPc}$ & PLGA & V-PPZ-NPs & 660 & - & 15 \\
\hline $\mathrm{ZnPc}$ & DSPS-PEG & DBCO-ZnPc-LP & 808 & 44.4 & 16 \\
\hline $\mathrm{ZnPc}$ & self-assembly nanoparticles & NanoPcTB & 655 & - & 17 \\
\hline $\mathrm{ZnPc}$ & self-assembly nanoparticles & PcS-MA & 655 & - & 18 \\
\hline $\mathrm{ZnPc}$ & self-assembly nanowire & $\mathrm{ZnPc} N W$ & 808 & - & 19 \\
\hline VONc & COFs & VONc@COF-Por (3) & 808 & 55.9 & This work \\
\hline
\end{tabular}
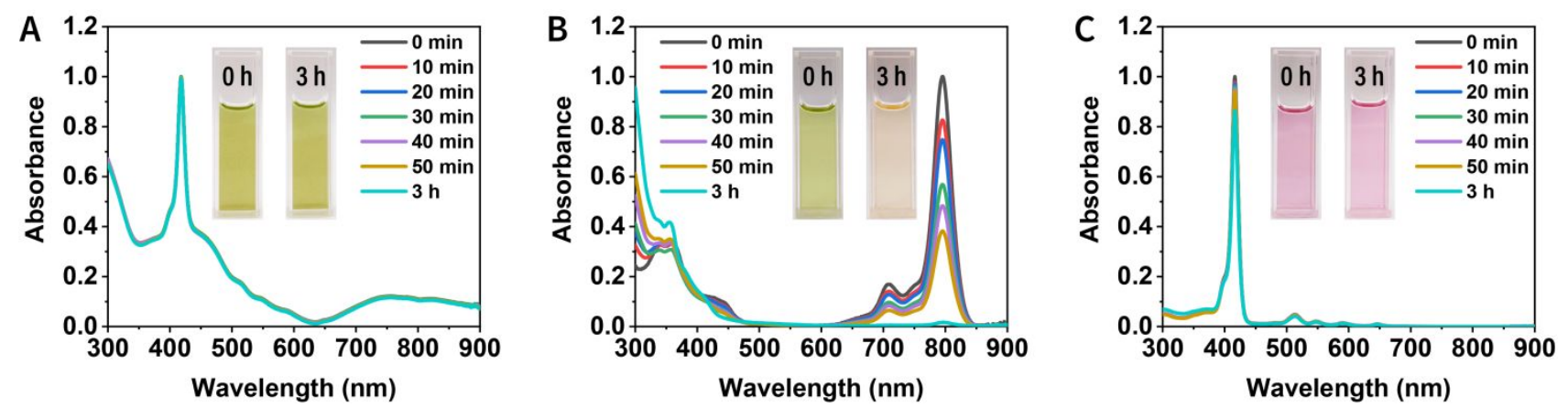

Figure S12. UV-vis spectra of 3 (A), VONc (B), Por (C) under a red LED (50 mW/cm²) and an $808 \mathrm{~nm}\left(1.5 \mathrm{~W} / \mathrm{cm}^{2}\right)$ irradiation laser for 3 h. Inset: Digital photos before and after irradiation.

\section{Subcellular Localization of Mitochondria}


Cells were seeded into glass bottom dishes and incubated overnight in a $\mathrm{CO}_{2}$ incubator. After removal of the culture medium, the cells were incubated with DPBS dispersion of $3(200 \mu \mathrm{L}, 40 \mu \mathrm{g} / \mathrm{mL})$ for $2 \mathrm{~h}$ in a $\mathrm{CO}_{2}$ incubator, and washed with DPBS twice carefully. After additional $4 \mathrm{~h}$ incubation, cells were incubated with MitoTracker Deep Red FM (200 $\mu \mathrm{L}, 25 \mathrm{nM})$ for an additional 10 min, and washed with DPBS twice. Finally, the laser scanning confocal fluorescence images were captured. The green images of $\mathbf{3}$ were excited by $488 \mathrm{~nm}$ light, and the emission wavelength range was collected at $540 \pm 20 \mathrm{~nm}$. The red images of mitochondria were excited by $633 \mathrm{~nm}$ light, and the emission wavelength range was collected at $665 \pm 20 \mathrm{~nm}$. Controls were conducted to make sure images were free of crosstalk. Colocalization was analyzed by ImageJ software.

\section{Subcellular Localization of Lysosomes}

Cells were seeded into glass bottom dishes and incubated overnight in a $\mathrm{CO}_{2}$ incubator. After removal of the culture medium, the cells were incubated with DPBS dispersion of $3(200 \mu \mathrm{L}, 40 \mu \mathrm{g} / \mathrm{mL})$ for $2 \mathrm{~h}$ in a $\mathrm{CO}_{2}$ incubator, and washed with DPBS twice carefully. After additional $4 \mathrm{~h}$ incubation, cells were incubated with LysoTracker Red DND-99 (200 $\mu \mathrm{L}, 50 \mathrm{nM})$ for an additional 10 min, and washed with DPBS twice. Finally, the laser scanning confocal fluorescence images were captured. The green images of $\mathbf{3}$ were excited by $488 \mathrm{~nm}$ light, and the emission wavelength range was collected at $540 \pm 20 \mathrm{~nm}$. The red images of lysosomes were excited by 561 $\mathrm{nm}$ light, and the emission wavelength range was collected at $590 \pm 20 \mathrm{~nm}$. Controls were conducted to make sure images were free of crosstalk. Colocalization was analyzed by ImageJ software.

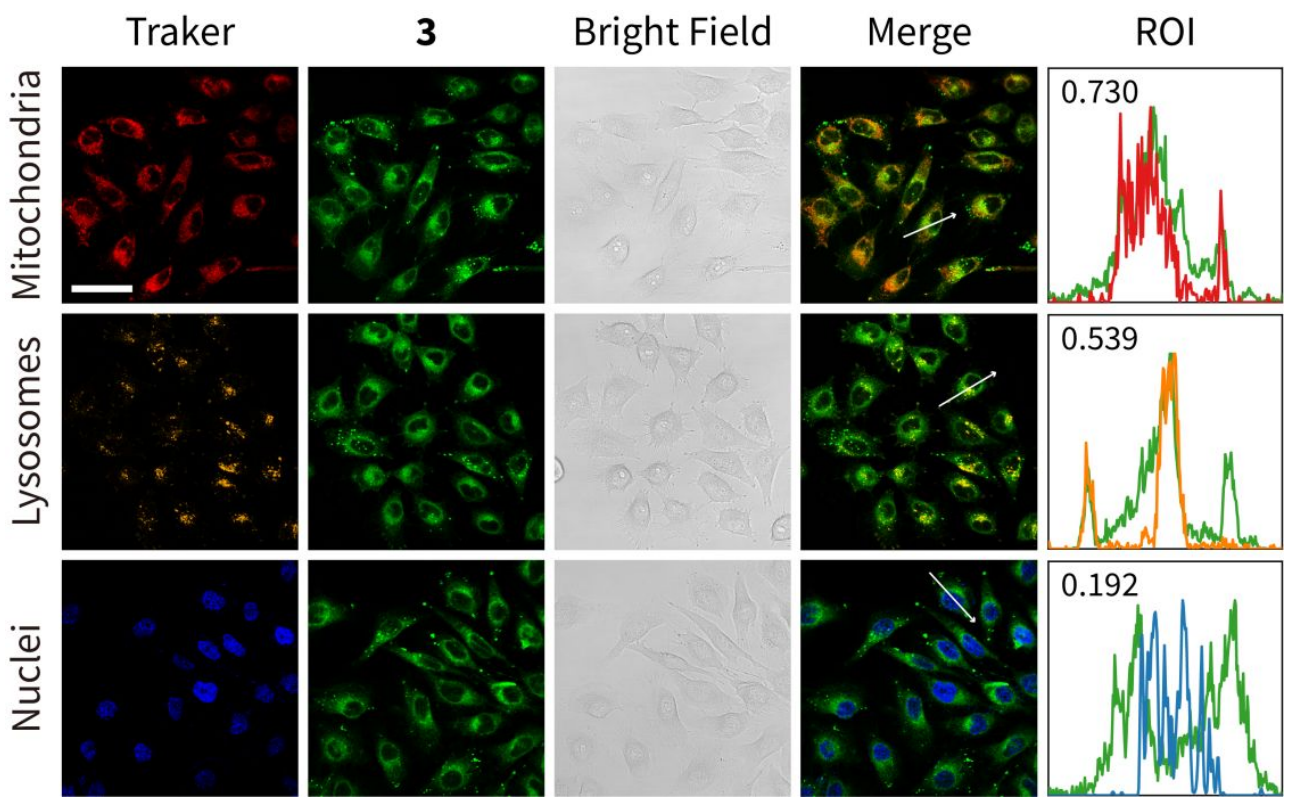

Figure S13. Subcellular localization of 3 in MCF-7 cells. The cells were pretreated with $\mathbf{3}(40 \mu \mathrm{g} / \mathrm{mL}, 2 \mathrm{~h})$, and subsequently coincubated with MitoTracker Deep Red FM (25 nM, 10 min), LysoTracker Red DND-99 (50 nM, 10 min), and Hoechst 33258 (10 $\mu \mathrm{M}, 10 \mathrm{~min}$ ) to label mitochondria, lysosomes, and nuclei, respectively. Scale bar, $50 \mu \mathrm{m}$.

\section{Subcellular Localization of Nuclei}

Cells were seeded into glass bottom dishes and incubated overnight in a $\mathrm{CO}_{2}$ incubator. After removal of the culture medium, the cells were incubated with DPBS dispersion of $3(200 \mu \mathrm{L}, 40 \mu \mathrm{g} / \mathrm{mL})$ for $2 \mathrm{~h}$ in a $\mathrm{CO}_{2}$ incubator, and washed with DPBS twice carefully. After additional $4 \mathrm{~h}$ incubation, cells were incubated with Hoechst $33258(200 \mu \mathrm{L}, 10 \mu \mathrm{M})$ for an additional 10 min, and washed with 
DPBS twice. Finally, the laser scanning confocal fluorescence images were captured. The green images of $\mathbf{3}$ were excited by $488 \mathrm{~nm}$ light, and the emission wavelength range was collected at $540 \pm 20 \mathrm{~nm}$. The blue images of nucleus were excited by $405 \mathrm{~nm}$ light, and the emission wavelength range was collected at $460 \pm 20 \mathrm{~nm}$. Controls were conducted to make sure images were free of crosstalk. Colocalization was analyzed by ImageJ software.

\section{Intracellular Singlet Oxygen Measurement}

Cells were seeded into glass bottom dishes and incubated overnight in a $\mathrm{CO}_{2}$ incubator. After removal of the culture medium, the cells were incubated with DPBS dispersion of $3(200 \mu \mathrm{L}, 40 \mu \mathrm{g} / \mathrm{mL})$ for $2 \mathrm{~h}$ in a $\mathrm{CO}_{2}$ incubator, and washed with DPBS twice carefully. Then, the cells were incubated with SOSG $(200 \mu \mathrm{L}, 5 \mu \mathrm{M})$ for $15 \mathrm{~min}$, and washed with DPBS twice carefully. For PTT, the cells were exposed to $808 \mathrm{~nm}$ laser $\left(1.5 \mathrm{~W} / \mathrm{cm}^{2}, 10 \mathrm{~min}\right)$. For PDT, the cells were exposed to red LED (50 $\left.\mathrm{mW} / \mathrm{cm}^{2}, 10 \mathrm{~min}\right)$. Finally, the laser scanning confocal fluorescence images were captured. The green images were excited by $488 \mathrm{~nm}$ light, and the emission wavelength range was collected at $525 \pm 20 \mathrm{~nm}$. Controls were conducted to make sure images were free of crosstalk. The mean fluorescence intensity (MFI) was analyzed by ImageJ software.

\section{Mitochondrial Membrane Potential}

Cells were seeded into glass bottom dishes and incubated overnight in a $\mathrm{CO}_{2}$ incubator. After removal of the culture medium, the cells were incubated with DPBS dispersion of $3(200 \mu \mathrm{L}, 40 \mu \mathrm{g} / \mathrm{mL})$ for $2 \mathrm{~h}$ in a $\mathrm{CO}_{2}$ incubator. For PTT, the cells were exposed to 808 $\mathrm{nm}$ laser $\left(1.5 \mathrm{~W} / \mathrm{cm}^{2}, 10 \mathrm{~min}\right)$. For PDT, the cells were exposed to red LED (50 mW/ $\left.\mathrm{cm}^{2}, 10 \mathrm{~min}\right)$. After additional $4 \mathrm{~h}$ incubation, the cells were incubated with $\mathrm{JC}-1(200 \mu \mathrm{L}, 10 \mu \mathrm{g} / \mathrm{mL})$ for $10 \mathrm{~min}$, washed with DPBS twice, and the laser scanning confocal fluorescence images were captured. The green images of monomer were excited by $488 \mathrm{~nm}$ light, and the emission wavelength range was collected at $530 \pm 15 \mathrm{~nm}$. The red images of $J$-aggregate were excited by $514 \mathrm{~nm}$ light, and the emission wavelength range was collected at $590 \pm 17 \mathrm{~nm}$. Controls were conducted to make sure images were free of crosstalk. The MFI was analyzed by ImageJ software.

\section{Mitochondrial Oxidative Stress}

Cells were seeded into glass bottom dishes and incubated overnight in a $\mathrm{CO}_{2}$ incubator. After removal of the culture medium, the cells were incubated with DPBS dispersion of $3(200 \mu \mathrm{L}, 40 \mu \mathrm{g} / \mathrm{mL})$ for $2 \mathrm{~h}$ in a $\mathrm{CO}_{2}$ incubator. For PTT, the cells were exposed to 808 $\mathrm{nm}$ laser $\left(1.5 \mathrm{~W} / \mathrm{cm}^{2}, 10 \mathrm{~min}\right)$. For PDT, the cells were exposed to red LED (50 mW/cm², $\left.10 \mathrm{~min}\right)$. After additional $4 \mathrm{~h}$ incubation, the cells were incubated with MitoTracker Red CM- $\mathrm{H}_{2}$ Xros $(200 \mu \mathrm{L}, 100 \mathrm{nM})$ for $10 \mathrm{~min}$, washed with DPBS twice, and the laser scanning confocal fluorescence images were captured. The yellow images were excited by $561 \mathrm{~nm}$ light, and the emission wavelength range was collected at $599 \pm 20 \mathrm{~nm}$. Controls were conducted to make sure images were free of crosstalk. The MFI was analyzed by ImageJ software.

\section{Lysosomal Membrane Permeabilization}


Cells were seeded into glass bottom dishes and incubated overnight in a $\mathrm{CO}_{2}$ incubator. After removal of the culture medium, the cells were incubated with DPBS dispersion of $3(200 \mu \mathrm{L}, 40 \mu \mathrm{g} / \mathrm{mL})$ for $2 \mathrm{~h}$ in a $\mathrm{CO}_{2}$ incubator. For PTT, the cells were exposed to 808 $\mathrm{nm}$ laser $\left(1.5 \mathrm{~W} / \mathrm{cm}^{2}, 10 \mathrm{~min}\right)$. For PDT, the cells were exposed to red LED (50 mW/ $\left.\mathrm{cm}^{2}, 10 \mathrm{~min}\right)$. After additional $4 \mathrm{~h}$ incubation, the cells were incubated with $\mathrm{AO}(200 \mu \mathrm{L}, 5 \mu \mathrm{g} / \mathrm{mL})$ for $10 \mathrm{~min}$, washed with DPBS twice, and the laser scanning confocal fluorescence images were captured. The green images were excited by $488 \mathrm{~nm}$ light, and the emission wavelength range was collected at $530 \pm 20 \mathrm{~nm}$. The red images were excited by $488 \mathrm{~nm}$ light, and the emission wavelength range was collected at $640 \pm 20 \mathrm{~nm}$. Controls were conducted to make sure images were free of crosstalk.

\section{In Vitro Antitumor Therapy}

Cells were seeded into 96-well plates with a cell number of $\sim 5 \mathrm{k}$ cells/well and incubated overnight in a $\mathrm{CO}_{2}$ incubator. After removal of the culture medium, the cells were incubated with DPBS dispersion of $3(100 \mu \mathrm{L}, 0-400 \mu \mathrm{g} / \mathrm{mL})$ for $2 \mathrm{~h}$ in a $\mathrm{CO}_{2}$ incubator. For PTT, the cells were exposed to $808 \mathrm{~nm}$ laser $\left(1.5 \mathrm{~W} / \mathrm{cm}^{2}, 10 \mathrm{~min}\right)$. For PDT, the cells were exposed to red LED (50 $\left.\mathrm{mW} / \mathrm{cm}^{2}, 10 \mathrm{~min}\right)$. When necessary, the 96 -well plates were placed at $4{ }^{\circ} \mathrm{C}$ to maintain a constant temperature, or $\mathrm{NaN}_{3}(25 \mathrm{mM})$ was added to scavenge ${ }^{1} \mathrm{O}_{2}$ generated during therapeutic process. After additional $24 \mathrm{~h}$ incubation, MTT $(10 \mu \mathrm{L}, 5 \mathrm{mg} / \mathrm{mL})$ was added to each well and incubated for additional $4 \mathrm{~h}$ in a $\mathrm{CO}_{2}$ incubator. Finally, the supernatants were removed and DMSO (100 $\left.\mu \mathrm{L}\right)$ was added into each well, followed by recording the absorbance at $490 \mathrm{~nm}$.

Table S2. Statistical analysis ( $p$ value) of in vitro antitumor therapy.

\begin{tabular}{lllllll}
\hline Concentration $/(\mu \mathrm{g} / \mathrm{mL})$ & 0 & 20 & 40 & 100 & 200 & 400 \\
\hline Dark $v$ PDT & $0.7598(\mathrm{~ns})$ & $0.1643(\mathrm{~ns})$ & $0.0081(* *)$ & $0.0015(* *)$ & $<0.0001(* * *)$ & $<0.0001(* * *)$ \\
Dark $v$ PTT & $0.9015(\mathrm{~ns})$ & $0.4588(\mathrm{~ns})$ & $0.0711(\mathrm{~ns})$ & $0.0002(* * *)$ & $<0.0001(* * *)$ & $<0.0001(* * *)$ \\
Dark $v$ PDT+PTT & $0.8941(\mathrm{~ns})$ & $0.0737(\mathrm{~ns})$ & $0.0006(* * *)$ & $<0.0001(* * *)$ & $<0.0001(* * *)$ & $<0.0001(* * *)$ \\
PDT $v$ PDT+PTT & $0.6157(\mathrm{~ns})$ & $0.7757(\mathrm{~ns})$ & $0.0056(* *)$ & $0.0003(* * *)$ & $0.0002(* * *)$ & $0.0031(* *)$ \\
PTT vs PDT+PTT & $0.9923(\mathrm{~ns})$ & $0.2370(\mathrm{~ns})$ & $0.0026(* *)$ & $0.0005(* * *)$ & $0.0110(*)$ & $0.0743(\mathrm{~ns})$ \\
\hline
\end{tabular}

$* * * p<0.001 ; * * p<0.01 ; * p<0.05 ; n s$, no significance $(p>0.05)$.

\section{Calcein-AM/PI Double Staining}

Cells were seeded into $35 \mathrm{~mm}$ culture dishes and incubated overnight in a $\mathrm{CO}_{2}$ incubator. After removal of the culture medium, the cells were incubated with DPBS dispersion of $3(1 \mathrm{~mL}, 100 \mu \mathrm{g} / \mathrm{mL})$ for $2 \mathrm{~h}$ in a $\mathrm{CO}_{2}$ incubator. For PTT, the cells were exposed to $808 \mathrm{~nm}$ laser $\left(1.5 \mathrm{~W} / \mathrm{cm}^{2}, 10 \mathrm{~min}\right)$. For PDT, the cells were exposed to red LED $\left(50 \mathrm{~mW} / \mathrm{cm}^{2}, 10 \mathrm{~min}\right)$. After additional $4 \mathrm{~h}$ incubation, the cells were collected using Trypsin-EDTA solution, washed with DPBS twice carefully, and incubated with calcein-AM (500 $\mu \mathrm{L}$, $2 \mu \mathrm{M})$ and PI (500 $\mu \mathrm{L}, 4 \mu \mathrm{M})$ for 15 min. Finally, the cells were washed with DPBS twice carefully, and imaged with a laser scanning confocal microscope. The green images of living cells were excited by $488 \mathrm{~nm}$ light, and the emission wavelength range was collected at $520 \pm 20 \mathrm{~nm}$. The red images of dead cells were excited by $514 \mathrm{~nm}$ light, and the emission wavelength range was collected at $640 \pm 20$ nm. 


\section{In Vitro Scratch Assay}

Cells were seeded into $35 \mathrm{~mm}$ culture dishes and grown to confluence in a $\mathrm{CO}_{2}$ incubator. Next, cell monolayer was damaged by scratching with a sterile $1000 \mu \mathrm{L}$ pipet tip to obtain scratches. Then, the cells were incubated with DPBS dispersion of 3 (1 mL, 40 $\mu \mathrm{g} / \mathrm{mL}$ ) for $2 \mathrm{~h}$ in a $\mathrm{CO}_{2}$ incubator. The $0 \mathrm{~h}$ reference images of the scratched areas were taken using inverted microscope. Then, for PTT, the cells were exposed to $808 \mathrm{~nm}$ laser $\left(1.5 \mathrm{~W} / \mathrm{cm}^{2}, 10 \mathrm{~min}\right)$; for PDT, the cells were exposed to red LED $\left(50 \mathrm{~mW} / \mathrm{cm}^{2}, 10 \mathrm{~min}\right)$. After additional $24 \mathrm{~h}$ incubation, the scratched areas were taken again. The scratch widths were measured by ImageJ software, and the width ratios of $0 \mathrm{~h}$ and $24 \mathrm{~h}$ were calculated. The data was the result of 3 independent experiments.

\section{In Vivo Antitumor Therapy}

MCF-7 cancer cells $\left(10^{6}\right.$ cells $)$ suspended in DPBS $(100 \mu \mathrm{L})$ were subcutaneously injected into the flanks of each mice to establish MCF-7 xenograft model. Length $(L)$ and width $(W)$ of the tumor were determined by digital calipers. The tumor volume $(V)$ was calculated by the formula $V=1 / 2 \times L \times \mathrm{W}^{2}$. When the tumor size reached $\sim 150 \mathrm{~mm}^{3}$, the nude mice bearing MCF-7 tumors $(n=30)$ were randomly distributed into 6 groups. (Table S3) After intratumoral injection, the nude mice were feeding for $4 \mathrm{~h}$, and for the treatment group, light treatment was performed on the tumor site. The mice continued to be fed for 15 days. The tumor volume and nude mouse body weight were recorded daily during the experimental period.

Table S3. Treatment plan of PDT and PTT experiments in vivo.

\begin{tabular}{lllllll}
\hline & Group & Injection & Concentration & Volume & Red Laser & $808 \mathrm{~nm}$ Laser \\
\hline i & Control & DPBS & - & $100 \mu \mathrm{L}$ & - & - \\
ii & Laser & DPBS & - & $100 \mu \mathrm{L}$ & $10 \mathrm{~min}, 50 \mathrm{~mW} / \mathrm{cm}^{2}$ & $10 \mathrm{~min}, 1.5 \mathrm{~W} / \mathrm{cm}^{2}$ \\
iii & Dark & DPBS dispersion of 3 & $600 \mu \mathrm{g} / \mathrm{mL}$ & $100 \mu \mathrm{L}$ & - & - \\
iv & PDT & DPBS dispersion of 3 & $600 \mu \mathrm{g} / \mathrm{mL}$ & $100 \mu \mathrm{L}$ & $10 \mathrm{~min}, 50 \mathrm{~mW} / \mathrm{cm}^{2}$ & - \\
$\mathbf{v}$ & PTT & DPBS dispersion of 3 & $600 \mu \mathrm{g} / \mathrm{mL}$ & $100 \mu \mathrm{L}$ & - & $10 \mathrm{~min}, 1.5 \mathrm{~W} / \mathrm{cm}^{2}$ \\
vi & PDT+PTT & DPBS dispersion of 3 & $600 \mu \mathrm{g} / \mathrm{mL}$ & $100 \mu \mathrm{L}$ & $10 \mathrm{~min}, 50 \mathrm{~mW} / \mathrm{cm}^{2}$ & $10 \mathrm{~min}, 1.5 \mathrm{~W} / \mathrm{cm}^{2}$ \\
\hline
\end{tabular}

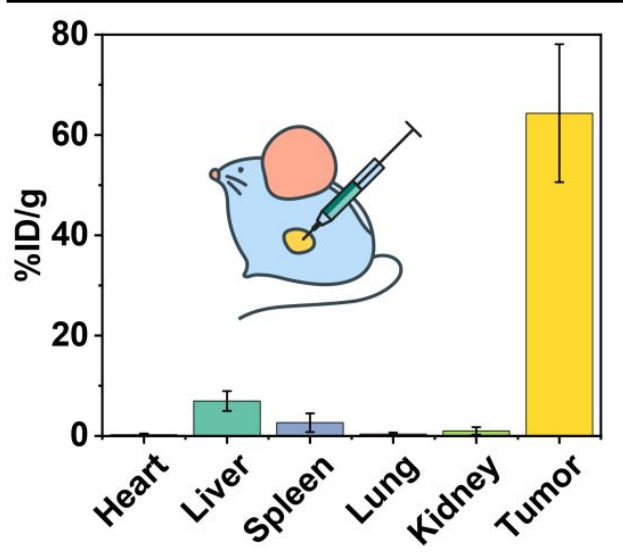

Figure S14. Biodistribution of V in the tumors and major organs of the mice at $4 \mathrm{~h}$ post intratumor injection of the $3(600 \mu \mathrm{g} / \mathrm{mL})$. The unit is the percentage of injected dose per gram of tissue $(\% \mathrm{ID} / \mathrm{g})$. 

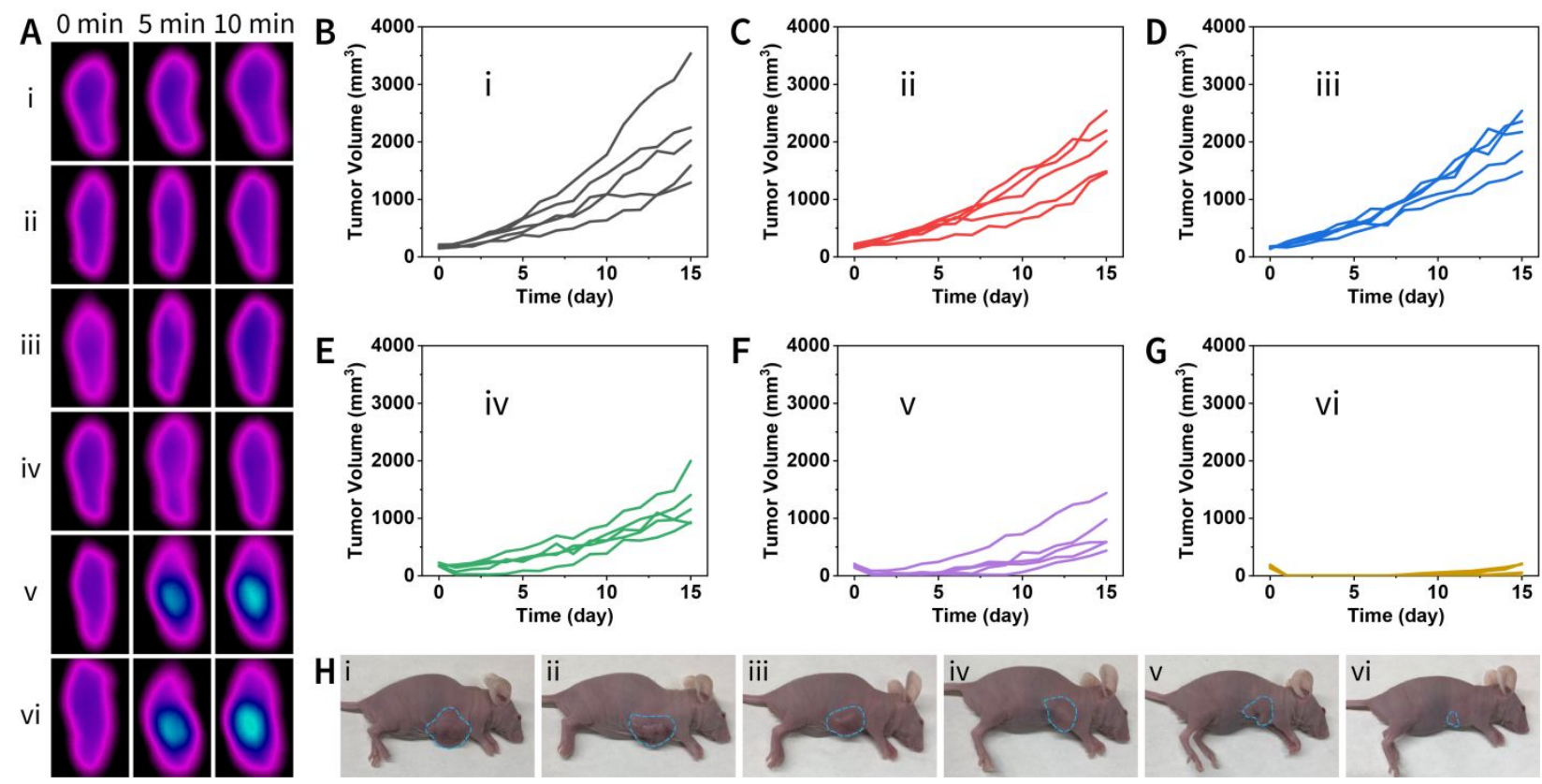

Figure S15. (A) Thermal imageries of the nude mice. (B, C, D, E, F, G) Tumor volume of each nude mice in various groups during the treatment. (H) Representative photographs of the nude mice at the end of the treatment.

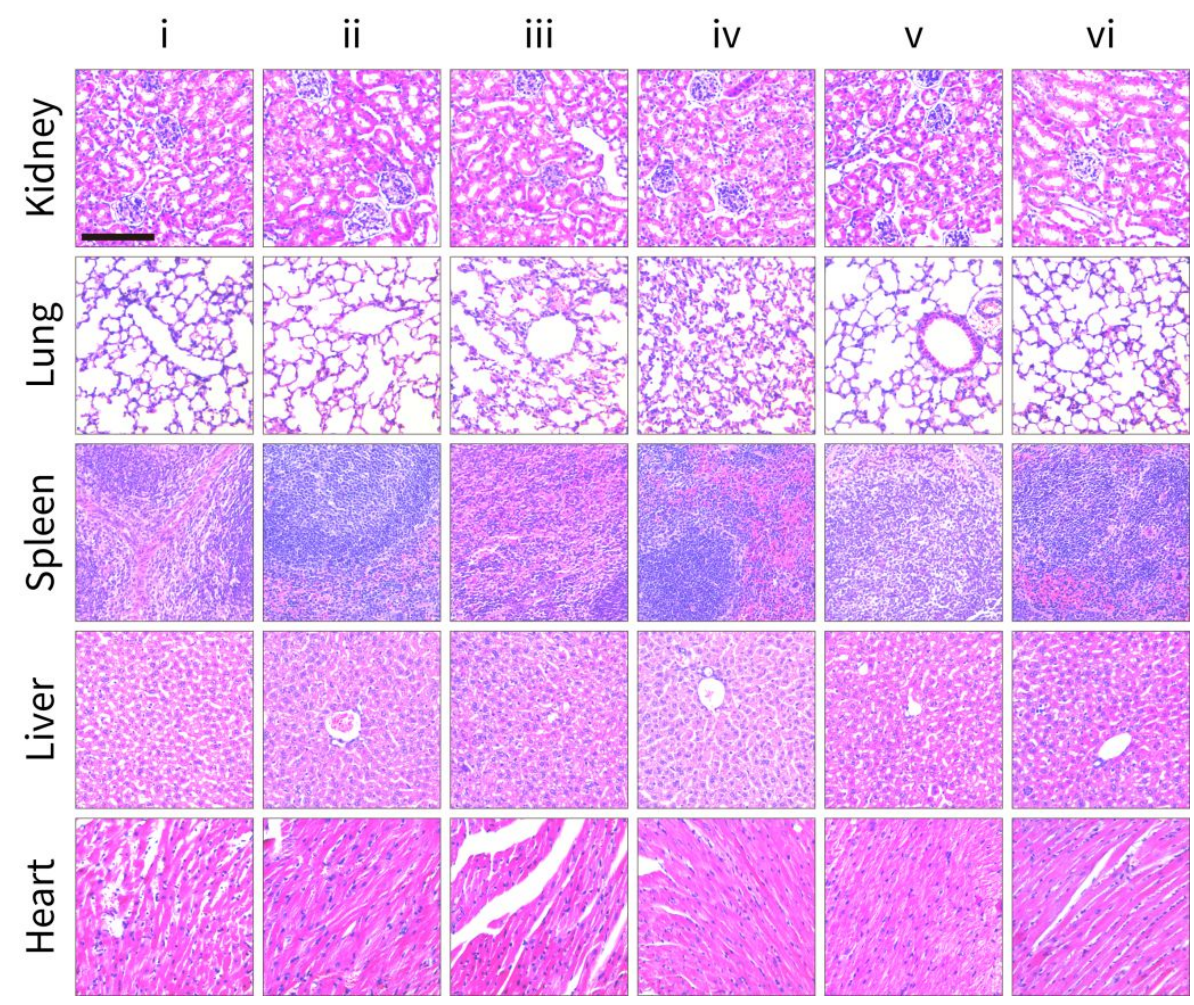

Figure S16. H\&E stained tissue sections from the heart, liver, spleen, lung, and kidney of the nude mice at the end of the treatment.

Scale bar, $100 \mu \mathrm{m}$.

\section{Enhanced In Vivo Antitumor Therapy}

The nude mice bearing MCF-7 tumors ( $n=15)$ were randomly distributed into 3 groups. (Table S4) After intratumoral injection, the nude mice were feeding for $4 \mathrm{~h}$, and for the treatment group, light treatment was performed on the tumor site. The mice continued to be fed for 15 days. The tumor volume and nude mouse body weight were recorded daily during the experimental period. 
Table S4. Treatment plan of enhanced PDT and PTT experiments in vivo.

\begin{tabular}{lllllll}
\hline & Group & Injection & Concentration & Volume & Red Laser & $808 \mathrm{~nm}$ Laser \\
\hline vii & Control & DPBS & - & $100 \mu \mathrm{L}$ & - & - \\
viii & Enhanced PDT & DPBS dispersion of $\mathbf{3}$ & $600 \mu \mathrm{g} / \mathrm{mL}$ & $100 \mu \mathrm{L}$ & $20 \mathrm{~min}, 200 \mathrm{~mW} / \mathrm{cm}^{2}$ & - \\
ix & Enhanced PTT & DPBS dispersion of $\mathbf{3}$ & $600 \mu \mathrm{g} / \mathrm{mL}$ & $100 \mu \mathrm{L}$ & - & $20 \mathrm{~min}, 2.0 \mathrm{~W} / \mathrm{cm}^{2}$ \\
\hline
\end{tabular}
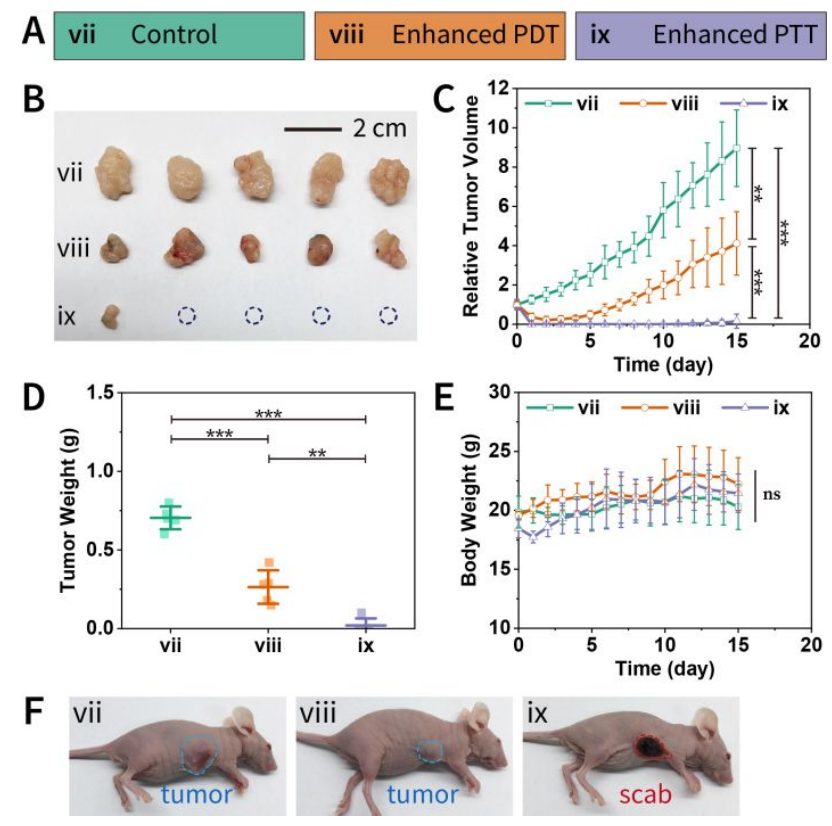

Figure S17. (A) Grouping situation. (B) Photographs of tumor tissue obtained after treatment. Scale bar, $2 \mathrm{~cm}$. (C) Tumor volume of the nude mice in various groups during the treatment. (D) Tumor weight obtained after treatment. (E) Body weight of the mice in various groups during the treatment. (F) Representative photographs of the nude mice at the end of the treatment. All data are presented as the mean $\pm \mathrm{SD}(n=5) .{ }^{* * *} p<0.001 ; * * p<0.01 ; n s$, no significance $(p>0.05)$.

\section{Supplemental References}

(1) Choi, H.; Lee, G.-H.; Kim, K. S.; Hahn, S. K. Light-Guided Nanomotor Systems for Autonomous Photothermal Cancer Therapy. ACS Appl. Mater. Interfaces 2018, 10, 2338-2346.

(2) Wei, J.-P.; Chen, X.-L.; Wang, X.-Y.; Li, J.-C.; Shi, S.-G.; Liu, G.; Zheng, N.-F. Polyethylene Glycol Phospholipids Encapsulated Silicon 2,3-Naphthalocyanine Dihydroxide Nanoparticles (SiNcOH-DSPE-PEG( $\left.\mathrm{NH}_{2}\right)$ NPs) for Single NIR Laser Induced Cancer Combination Therapy. Chin. Chem. Lett. 2017, 28, 1290-1299.

(3) Taratula, O.; Doddapaneni, B. S.; Schumann, C.; Li, X.; Bracha, S.; Milovancev, M.; Alani, A. W. G.; Taratula, O. Naphthalocyanine-Based Biodegradable Polymeric Nanoparticles for Image-Guided Combinatorial Phototherapy. Chem. Mater. 2015, $27,6155-6165$. 
(4) Li, L.; Yang, Q.; Shi, L.; Zheng, N.; Li, Z.; Li, K.; Qiao, S.; Jia, T.; Sun, T.; Wang, Y. Novel Phthalocyanine-Based Polymeric Micelles with High Near-Infrared Photothermal Conversion Efficiency under $808 \mathrm{~nm}$ Laser Irradiation for In Vivo Cancer Therapy. J. Mater. Chem. B 2019, 7, 2247-2251.

(5) Lim, C.-K.; Shin, J.; Lee, Y.-D.; Kim, J.; Oh, K. S.; Yuk, S. H.; Jeong, S. Y.; Kwon, I. C.; Kim, S. Phthalocyanine-Aggregated Polymeric Nanoparticles as Tumor-Homing Near-Infrared Absorbers for Photothermal Therapy of Cancer. Theranostics 2012, 2, 871879.

(6) Peng, J.; Zhao, L.; Zhu, X.; Sun, Y.; Feng, W.; Gao, Y.; Wang, L.; Li, F. Hollow Silica Nanoparticles Loaded with Hydrophobic Phthalocyanine for Near-Infrared Photodynamic and Photothermal Combination Therapy. Biomaterials 2013, 34, 7905-7912.

(7) Zeng, K.; Xu, Q.; Ouyang, J.; Han, Y.; Sheng, J.; Wen, M.; Chen, W.; Liu, Y.-N. Coordination Nanosheets of Phthalocyanine as Multifunctional Platform for Imaging-Guided Synergistic Therapy of Cancer. ACS Appl. Mater. Interfaces 2019, 11, $6840-6849$.

(8) Zhu, X.; Li, J.; Qiu, X.; Liu, Y.; Feng, W.; Li, F. Upconversion Nanocomposite for Programming Combination Cancer Therapy by Precise Control of Microscopic Temperature. Nat. Commun. 2018, 9, 2176.

(9) Jia, Q.; Ge, J.; Liu, W.; Zheng, X.; Wang, M.; Zhang, H.; Wang, P. Biocompatible Iron Phthalocyanine-Albumin Assemblies as Photoacoustic and Thermal Theranostics in Living Mice. ACS Appl. Mater. Interfaces 2017, 9, 21124-21132.

(10) Tan, J.; Meeprasert, J.; Ding, Y.; Namuangruk, S.; Ding, X.; Wang, C.; Guo, J. Cyclomatrix Polyphosphazene Porous Networks with J-Aggregated Multiphthalocyanine Arrays for Dual-Modality Near-Infrared Photosensitizers. ACS Appl. Mater. Interfaces 2018, $10,40132-40140$.

(11) Ma, J.; Chen, D.; Li, Y.; Chen, Y.; Liu, Q.; Zhou, X.; Qian, K.; Li, Z.; Ruan, H.; Hou, Z.; Zhu, X. Zinc Phthalocyanine-Soybean Phospholipid Complex Based Drug Carrier for Switchable Photoacoustic/Fluorescence Image, Multiphase Photothermal/Photodynamic Treatment and Synergetic Therapy. J. Control. Release 2018, 284, 1-14.

(12) Jin, H.-G.; Zhong, W.; Yin, S.; Zhang, X.; Zhao, Y.-H.; Wang, Y.; Yuan, L.; Zhang, X.-B. Lesson from Nature: Biomimetic Self-Assembling Phthalocyanines for High-Efficient Photothermal Therapy within the Biological Transparent Window. ACS Appl. Mater. Interfaces 2019, 11, 3800-3808.

(13) Wang, Z.; Gai, S.; Wang, C.; Yang, G.; Zhong, C.; Dai, Y.; He, F.; Yang, D.; Yang, P. Self-Assembled Zinc Phthalocyanine Nanoparticles as Excellent Photothermal/Photodynamic Synergistic Agent for Antitumor Treatment. Chem. Eng. J. 2019, 361, 117128.

(14) Sun, X.; Zhuang, B.; Zhang, M.; Jiang, H.; Jin, Y. Intratumorally Injected Photothermal Agent-Loaded Photodynamic Nanocarriers for Ablation of Orthotopic Melanoma and Breast Cancer. ACS Biomater. Sci. Eng. 2019, 5, 724-739.

(15) Chen, Y.-1.; Liu, F.-q.; Guo, Y.; Cheng, J.; Yang, L.; Lu, M.; Li, P.; Xu, J.; Yu, T.; Wang, Z.-g.; Cao, Y.; Ran, H.-t. PA/US Dual-Modality Imaging to Guide VEGFR-2 Targeted Photothermal Therapy Using ZnPc-/PFH-Loaded Polymeric Nanoparticles. Biomater. Sci. 2018, 6, 2130-2143. 
(16) Du, L.; Qin, H.; Ma, T.; Zhang, T.; Xing, D. In Vivo Imaging-Guided Photothermal/Photoacoustic Synergistic Therapy with Bioorthogonal Metabolic Glycoengineering-Activated Tumor Targeting Nanoparticles. ACS Nano 2017, 11, 8930-8943.

(17) Li, X.; Kim, C. y.; Lee, S.; Lee, D.; Chung, H.-M.; Kim, G.; Heo, S.-H.; Kim, C.; Hong, K.-S.; Yoon, J. Nanostructured Phthalocyanine Assemblies with Protein-Driven Switchable Photoactivities for Biophotonic Imaging and Therapy. J. Am. Chem. Soc. 2017, 139, 10880-10886.

(18) Li, X.; Yu, S.; Lee, D.; Kim, G.; Lee, B.; Cho, Y.; Zheng, B.-Y.; Ke, M.-R.; Huang, J.-D.; Nam, K. T.; Chen, X.; Yoon, J. Facile Supramolecular Approach to Nucleic-Acid-Driven Activatable Nanotheranostics that Overcome Drawbacks of Photodynamic Therapy. ACS Nano 2018, 12, 681-688.

(19) Moon, H. K.; Son, M.; Park, J. E.; Yoon, S. M.; Lee, S. H.; Choi, H. C. Significant Increase in the Water Dispersibility of Zinc Phthalocyanine Nanowires and Applications in Cancer Phototherapy. NPG Asia Mater. 2012, 4, e12. 